\title{
Allais, Stability, and Liapunov Theory
}

\author{
E. Roy Weintraub
}

There is a troublesome problem embedded in every discussion of scientific discovery. As the eminent historian of science Thomas S. Kuhn has remarked:

To make a discovery is to achieve one of the closest approximations to a property right that the scientific career affords. Professional prestige is often closely associated with these acquisitions. Small wonder, then, that acrimonious disputes about priority and independence in discovery have often marred the normally placid tenor of scientific communication. Even less wonder that many historians of science have seen the individual discovery as an appropriate unit with which to measure scientific progress and have devoted much time and skill to determining what man made which discovery at what point in time. $(1977,166)$

In economics, where discovery is less problematic than is success in solving some recognized problem or resolving some apparent paradox, the questions of priority are no less acrimonious and the claims made on behalf of particular economists are no less strident. ${ }^{1}$ My own previous studies in the modern history of general equilibrium analysis have proved to be more of a minefield than I had expected. The "simultaneous" nature of the proofs of existence of a competitive equilibrium by Arrow and Debreu and by McKenzie-which were publicly presented within twenty-four hours of each other (Weintraub 1985, 104)-and the fact that both Arrow and Debreu have been awarded Nobel Memorial Prizes on the basis of that work while McKenzie has not, and that there are those who refer to the Arrow-Debreu model whereas others refer to the Arrow-Debreu-McKenzie model, should have alerted me to the presence of as yet unresolved issues. Similarly, the question of the first use of Liapunov theory in economics, a leitmotif in my discussion of Takuma Yasui's early use of that theory (Weintraub 1987), led to some strong claims on behalf of Michio Morishima's early use of those same tools (Morishima 1980).

Correspondence may be addressed to the author, Department of Economics, Duke University, Durham NC 27706.

1. For an early, and now classical view of these matters in science see Merton 1957. 
The issue of priority is bafflingly complex. Is priority given to the first use? The first approximate use? The first successful use? And so on. Specifically, for Liapunov analysis and economic stability theory, the first Liapunov-function-based proof is generally said to be that of Arrow, Block, and Hurwicz in 1959. But Yasui, and Morishima, writing in Japanese, used Liapunov functions as early as the late 1940s. Hahn (1983, 50-51) claims that Samuelson's discussion on page 438 of Foundations of Economic Analysis (1947) "was within a hair's breadth of a development [Liapunov's method] that did not occur for another ten years."

It is this context which has sensitized me to the fact that the 1988 Nobel Memorial Prize awarded, most appropriately, to the eminent French economist Maurice Allais has been associated with some problematic claims made on his behalf. Since I have been considering the development of the literature on dynamics and stability, with a focus on the period from 1939 to 1958, and since claims made on behalf of Allais concern priority for his work in stability theory in that period, I may be able to bring the discussion into a sharper focus.

The central problem can be simply stated. In The New Palgrave, Bernard Belloc and Michel Moreaux, the authors of the entry on Allais, write:

It is impressive that the research programme defined at the start in Allais (1943) has been almost wholly fulfilled, even though some of the initial basic assumptions have been drastically revised. . . . [In his 1943 book] Allais gives the earliest formulation of an intertemporal general equilibrium and, in particular, all the arbitrage conditions between capital goods and land are made explicit. Then the first results on global stability of Walrasian tâtonnement are proved by means of Lyapunov's second method under assumptions equivalent to gross substitutability (cf. Negishi, Econometrica (1962), for a report in English). (Belloc and Moreaux 1987; emphasis mine)

Further, the distinguished mathematical economist Jean-Michel Grandmont wrote in his "Report on M. Allais' Scientific Work" (1988) that

M. Allais proved stability of equilibrium under assumptions which, taken together, are essentially the same as gross substitutability, and through an argument that in fact uses [the] Lyapounov stability method (1907). This discovery occurred well before K. Arrow and L. Hurwicz' innovative study of the issue (1958). M. Allais' priority is in particular established by T. Negishi in his survey (1962, p. 656).

The passage is then footnoted as follows:

Allais' proof was not entirely correct, as the Lyapounov function he used was not differentiable everywhere. He may be forgiven, per- 
haps, for having overlooked this technical point . . . [ellipsis in original]

Since this claim about Allais's work is based on a particular way in which history is constructed, it is important to be clear not only about that claim but about the historiographic issue from which it follows. My own claim is that the history of economic analysis is constructed, not found, and that historians construct by providing reinterpretations of apparently "fixed" texts. So too "priority" is constructed, not discovered and then awarded. In what follows, my discussion of Allais's work on stability provides the case study for the discussion of the historiographical problem.

\section{Negishi on Allais}

Section 6 of Negishi's "Stability of a Competitive Economy: A Survey Article" (1962) is titled "A Contribution of Maurice Allais." It is important to be explicit about Negishi's notice of Allais's work, because the claims of Belloc and Moreaux, and of Grandmont, rest on Negishi's authority. ${ }^{2}$

A brief comment may be appropriate on the significance of the rather neglected contribution to this field [stability theory] by M. Allais in 1943. [The attached reference cites Traité d'économie pure, Paris: Imprimerie Nationale, 2:486-89]. The stability of the Walrasian tâtonnement is discussed. It must be mentioned first that the original model of the tâtonnement due to Allais is not our tâtonnement process $(T)$ in the sense that price adjustment is assumed to take place not simultaneously in all markets but successively in one market after another. . . . Secondly, it must be noted that Allais did not assume gross substitutionality $(S)$ explicitly but made assumptions which, taken together, are essentially the same as gross substitutionality $(S)$.

Admitting these points, we can reconstruct Allais' argument in terms of our own model $(T)$ under assumptions $(S)$ and $(W)$ [where $(W)$ is Walras's Law]. It will be shown that Allais' argument, if properly reformulated, is the proof of the stability by the method of Lyapunov, i.e., by the use of a function decreasing through time. (Negishi 1962, 656)

We can be quite clear here. Negishi nowhere claimed that Allais proved the major stability theorem relating gross substitutionality to stability of the tâtonnement process. Neither did Negishi claim that

2. This is reinforced by a letter I received from Michel Moreaux (6 September 1989), in which he mentions that "you can find a brief and excellent account of Allais' contribution in T. Negishi." 
Allais had rediscovered, or even used, Liapunov theory. But Negishi was able to reconstruct one of Allais's arguments in terms of the modern treatment of stability via Liapunov's indirect method. Such a reconstruction is equivalent to a restatement of a Marxian argument in terms of a three-sector linear model: such a reconstruction is not, however, a demonstration that Marx proved, or knew, the second fundamental theorem of linear programming. Belloc and Moreaux, and Grandmont, cite Negishi to support their own claims for Allais's "priority." But Negishi nowhere states anything which allows such a claim to be made, nor does his own treatment of Allais's work on "stability" permit such an interpretation.

If there is claim to be made on behalf of Allais, it must be made by examining Allais's work itself. An argument from Negishi's authority is impermissible.

\section{Allais's Reflections on His Contribution}

Suppose Negishi was wrong, and Allais had in fact proved what Grandmont, and Belloc and Moreaux, claimed he had proved? That he might have done so is not unreasonable, on the face of it, for he was certainly able enough and interested enough to have done so. Further, he had access, in a way English-speaking economists did not, to the dynamic analysis of Poincaré and Liapunov, whose original Russian thesis had been translated and published in French in 1907. One of the ways in which we can assess this possibility is to consider what Allais himself believes he has contributed to economic analysis. We have available to us the remarkable document Contributions à la science économique: vue d'ensemble, 1943-1978 (Allais 1978), published under the auspices of the Centre National de la Recherche Scientifique, in which he reviews his own writings, over the thirty-five years of his published record, and presents what he believes are his significant contributions to the many fields and subfields, problems and analyses, in which he worked so brilliantly.

We are concerned here with part 2 of that book, "Théories de l'évolution et de l'équilibre économique général, de l'efficacité maximale et des fondements du calcul économique." There Allais summarizes, and reemphasizes, the important results he had obtained in his various writings. The topics are laid out systematically, and within each topic section he traces chronologically his own writings on the topic. After an overview, he opens with a reassessment of the major work at issue here, his 1943 book A la recherche d'une discipline économique: première partie, L'économie pure (Paris: Ateliers Industria).

He begins reconstructing his contributions by noting that he has gone through the exercise before, in the introduction to the 1952 reprint edition of the book: 
Dans l'Introduction à la deuxième [édition] de 1952, j'ai analysé les apports originaux que je pense avoir présentés dans cet ouvrage et je ne puis qu'y renvoyer. Cependant, je crois devoir mentionner ici ceux de ces apports qui, avec le recul du temps, m'apparaissent comme les plus importants. (32)

(In the introduction to the second edition of 1952 I analyzed those original contributions which I think I presented in that work. . . . However, I believe that I ought to mention here some of those contributions which, with the passage of time, appear to me as the more important ones.) $)^{3}$

He then goes on to list, in order, the ideas and arguments and contributions which he believes were significant. Sixth on the list is "Démonstration de la stabilité de l'équilibre dans le cas d'une économie walrasienne" (Demonstration of the stability of equilibrium in the case of a Walrasian economy). This is followed by a footnote reference to Allais 1943, 486-93.

He concludes this section with the sentence "Sur tous ces points, il $s$ 'agit de contributions entièrement nouvelles pour lesquelles il n' existe rien d'équivalent dans la littérature antérieure" (On all these points, those contributions were entirely new, and there existed no equivalent work in the previous literature) $(1978,34)$. To this he appends the following footnote:

Quelques favorables qu'aient été les analyses de mon ouvrage de 1943 , leurs auteurs n'ont pas aperçu la plupart des apports originaux que je viens de rappeler. Cependant cette circonstance n'est paradoxale qu'en apparence. La raison en est en effet l'incapacité des critiques d'apprécier tout apport que leurs réflexions antérieures ne leur ont déjà pas permis d'apercevoir plus ou moins confusément.

(However favorable were the discussions of my 1943 work, the authors did not notice most of the original contributions which I have recalled here. Yet this is not as paradoxical as it may appear. The reason is essentially the inability of the critics to appreciate any contribution that their own thinking at the time does not already allow them to understand more or less confusedly.)

Allais certainly believed that he had demonstrated the stability of equilibrium for a Walrasian multimarket system. Just as certainly he appears to believe that his own contribution was original and represents a break with, an improvement on, the past work, which in this case must

3. My loose translations of the French may be of some help to readers who wish to keep the argument in view without dictionary in hand. 
mean the work of Samuelson and Hicks, not Pareto and Walras. Is this the case?

Before addressing this issue, I reiterate that nowhere does Allais claim, in this 1978 reconsideration, that he used, or understood, or even was aware of Liapunov theory. In his set of strong claims about originality and priority there is no mention whatever of the technique used to prove stability. Failing to find such a claim made on his own behalf, in a context in which such a claim would have been natural, must make one suspicious of the contrary claim by Grandmont and by Belloc and Moreaux.

\section{The 1943 Stability Analysis}

It remains, then, to examine the claim that in his 1943 book (1) Allais used explicit Liapunov methods and/or (2) used the indirect Liapunov methods implicitly and/or (3) provided a proof of the stability of the Walrasian multimarket system.

The first claim can be easily dismissed. Allais 1943, 486-93, contains no mention of Liapunov theory, and no function or analysis is identified as Liapunov's indirect method.

Negishi was correct, however, in noting that Allais's analysis could be redone using the language of Liapunov theory. (Indeed, Hicks's stability analysis could be so reconstructed, likewise Samuelson's, and even Walras'; and so on). To see this, and to appraise the claim that Allais had proved, twenty-five years before Arrow and Hurwicz, the stability of a Walrasian multimarket system, it is necessary to take up Allais's 1943 analysis in a bit more detail.

He begins in section 193 by arguing that

Le principe de cette démonstration est essentiallement le suivant:

Si l'on considère la somme

$$
\mathscr{H}=\sum_{\mathscr{B}}\left|\mathscr{B}_{i}-\mathscr{B}\right|
$$

des valeurs absolues des différences entre les valeurs des offres et celles des demandes, il est possible de montrer, sous certaines conditions vraisemblables, que cette somme que nous appelerons "fonction caractéristique," ne peut que décroître, lorsqu'un marché élémentaire quelconque évolue conformément à la loi d'évolution des prix. $(1978,486-87)$

(The main idea of this proof is essentially the following: if one considers the sum $\mathscr{H}$ of the values of supply and demand, it is 
possible to show, under certain reasonable conditions, that this sum, which we call the characteristic function, can only decrease, when one arbitrary market evolves in conformity with the law of the evolution of price.)

It is immediately obvious that this sum, over all markets, of the difference in value between supply and demand, what Allais calls a "characteristic function," is or can be construed as a Liapunov function, and his comment that it will be seen to decrease over the time of operation of the law of markets (the tâtonnement really) appears to be the modern proof of stability of multimarket equilibrium. It is not, however, that modern proof at all. One must guard very carefully against reading a historical text against a context which misconstrues it. Looking for Liapunov functions in Allais leads a modern reader to "see" a proof of a time-decreasing (Liapunov) "characteristic function" when in fact no such proof is presented. What Allais is concerned to show, rather, is that in a neighborhood of equilibrium that function is a decreasing function of its argument, but that argument is not "time," and no differential or difference techniques are used in Allais's analysis.

How then does Allais show that his function decreases if markets are not in equilibrium? He begins with Lemma 1, which he identifies as "Variation avec le prix de l'excès de la valeur de la demande sur celle de l'offre" (Variation with price of the excess of the value of demand over that of supply) (497). He here attempts to show-and this is the first use of the term "neighborhood" in economic theory-that "au voisinage de l'équilibre, et pour des prix croissants, la valeur de l'offre croît plus vite que celle de la demande" (in a neighborhood of equilibrium, and for increasing prices, the value of supply increases more quickly than that of demand) (488, emphasis his). Put another way, in the case of usual markets, holding all other markets fixed whether in equilibrium or out and allowing the one market to adjust, near-equilibrium the law of markets (prices move with excess demand) reduces the value of that excess demand, and this is true as long as that market is not in equilibrium. Notice, however, that this argument is based on the specific form of the supply and demand relationships, that these assumptions are not made explicit, and that the structure of the proof is to consider markets one at a time.

What is necessary, of course, for a proof is a demonstration that if other markets are allowed to react to the adjustment in the first market, the induced disequilibria themselves are meliorated. This is discussed in Lemma 2, "Répercussion sur les autres marchés" (Repercussions in other markets) (489). Allais breaks up the value of the excess demands into those that move directly with price, and those that move inversely with price: 
Si en effet sur un marché donné la répercussion de la variation du prix a une incidence plus faible sur les valeurs des demandes que sur celles des offres, cela signifie que, d'une manière générale, l'incidence de la variation du prix considérée est plus faible sur les déterminations des demandeurs que sur celles des offres, d'où l'inégalité $\left[0<\delta \mathscr{B}^{y}-\delta \mathscr{B}_{i}{ }^{y}<\delta \mathscr{B}_{i}{ }^{x}-\delta \mathscr{B}^{x}\right]$. (489)

(Indeed, if on a given market the repercussion of the variation of the price has a weaker effect on the value of demand than on the value of supply, that means that, in general, the effect of the price variation is weaker in the determination of demand than on that of supply, so that one has the inequality [where $\delta$ represents a "small change" in the variable in a neighborhood of equilibrium].)

In other words, Allais separated those commodities the value of whose excess demands moved in one direction as price rose, from those commodities which moved in the other direction. The problem was clearly to show that the value of all excess demands in all the markets, taken in the aggregate as the algebraic sum of the two commodity groups' values, was falling as long as all markets were not in equilibrium. To accomplish this demonstration thus required an argument to show that those values which fell "outweighed" those which rose. Allais discusses this in a series of cases in which he breaks up the value movements into those goods whose excess demand value moves directly with the price movement in market $i$, and those whose excess demand value moves inversely with the price movement in market $i$. This certainly functions in the manner of the Hicksian division of commodities into the substitute and complement groups, though Allais nowhere makes any assumption about the character of the goods in terms of substitutability. What he has then established is an argument to the effect that each market, taken individually, will lead to a reduction of the deviation from equilibrium. Moving through each market in this way will allow the conclusion that, near equilibrium, $\delta \mathscr{H}<0$, or that the characteristic function decreases as long as equilibrium has not been established. What remains to be shown, however, is that all these adjustments can be effected simultaneously in the sense that the adjustment is market $j$ in response to the disequilibrium in market $i$ will not, in fact, lead to a further perturbation in market $i$ in a deviation-amplifying manner.

This step is not taken. Instead Allais's argument goes on to state that if the result is true in $n-1$ markets, then by the global budget constraint (Walras's Law) the result must be true in the $n$th market as well:

Dans le cas d'une économie walrasienne, lorsque l'égalité de l'offre et de la demande est réalisé pour $(n-1)$ bien elle est également 
vérifiée pour le $n^{\mathrm{e}}$ bien en raison de l'équation globale du budget $\Sigma\left(\mathscr{B}_{i}-\mathscr{B}\right)=0$ qui reste constamment vérifiée. (492)

(In the case of a Walrasian economy, when the equality of supply and demand is realized for $(n-1)$ goods it is equally realized for the $n$th good because of the global budget equation ... which remains always true.)

\section{Walras, Not Arrow-Block-Hurwicz}

It is important to be clear that Allais's analysis of the stability of equilibrium was certainly an improvement on Hicks's in the sense that stability itself was well-defined as a property of equilibria, and the issue was to establish that a Walrasian market equilibrium was stable. Hicks, recall, simply argued that "stable" was equivalent to an equilibrium's being a "maximum"; this was what produced the Hicksian stability conditions as second-order conditions. Allais, in contrast, appears to have understood that a proof of stability required an argument that discrepancies from equilibrium would be eliminated by the market activity itself. His arguments were designed to demonstrate that a measure of the discrepancy, his "characteristic function," took on smaller and smaller values as market forces acted in disequilibrium states, and that the change was proportional to the discrepancy.

Note, however, the problem thai Walras himself addressed. As Patinkin has argued:

[Walras] realized that a tâtonnement on one price which brings it to equilibrium will generally, because of the interdependence of the system, disturb the equilibrium of other markets. But he argued that the direct pressure of excess demand in a given market definitely pushed its price toward its equilibrium level, while the changes in other prices "exerted indirect influences, some in the direction of equality and others in the opposite direction ... so that up to a certain point they cancelled each other out. Hence the new system of prices ... is closer to equilibrium than the old system ...; and it is only necessary to continue this process along the same lines for the system to move closer and closer to equilibrium." [The attached reference cites Walras, Elements of Pure Economics, 1954, Jaffé's translation from the definitive 1926 Paris edition.] (Patinkin 1965, 535)

Put this way, Allais was simply formalizing the argument of marketby-market adjustment originally presented by Walras, with a sophisticated treatment of the intermarket interdependencies and an argument that the destabilizing movements would be outweighed by the stabilizing movements. 
It is very difficult to unsee the "true" theorem associated with this demonstration. Since we "know" that the tâtonnement, in its presentation as a set of simultaneous autonomous differential equations for the multimarket system, will lead globally asympotically to an equilibrium if Walras's Law holds, if the system is continuously differentiable, and homogeneous in prices and income, and gross substitutability prevails, it is hard to disconnect Allais's argument from the later proofs. Allais, of course, assumed a global budget constraint, or Walras's Law. His demand and supply functions were drawn as though they were quite wellbehaved, and thus could be taken to provide excess demand functions which were continuously differentiable and homogeneous. In order to claim that Allais gave the first real proof, then, it is sufficient to assert that he assumed gross substitutability. This is, in fact, the claim put forth by Grandmont: "The conditions postulated by Allais to show that the Lyapounov function decreases along a tâtonnement are essentially that when the price of a commodity (good or service) goes up, excess supply goes up, i.e. excess demand goes down, which is essentially gross substitutability" (personal correspondence, 14 March 1989, p. 2).

The argument is that Allais assumed gross substitutability. In fact, Allais did write that "au voisinage de l'équilibre, et pour des prix croissants, la valeur de l'offre croît plus vite que celle de la demande. On retrouve ainsi une propriété que l'on peut considérer comme établie par l'expérience" (in a neighborhood of the equilibrium, and for increasing price, the value of supply is increasing faster than that of demand. One thus finds a property which one can consider as established by experience) (488). The four footnotes attached to the first sentence, however, make clear what is going on. The first (note 5) concerns the fact that individuals should have similar tastes and wealth: "Si les psychologies et les ressources des individus étaient identiques, on aurait ..." (If the psychologies and the resources of the individuals were identical, one would have ....). The second (note 6) says "La démonstration faite n'est valable qu'au voisinage de l'équilibre ..." (The proof is valid only in a neighborhood of equilibrium). The third (note 7) argues that when all individuals are essentially the same, the equilibrium will be stable. Finally, the fourth (note 8 ) states that individuals may be sufficiently similar for them to be taken as essentially identical if one considers them to be statistically associated with a median individual.

In other words, Allais based his argument on the assumption that aggregate excess demands would behave exactly as individual excess demands. But since individual excess demands for a good are taken to move with the price of that good in accord with substitutability (Allais does believe that demand curves slope downward, etc.), he infers that market excess demands can be so described. 
What Allais takes to discuss stability, his characteristic function, is the discrepancy between the supply and demand curves, the values of supply and demand. Certainly there is no discrepancy in equilibrium, for that condition defines equilibrium. And second, it is certain that if the discrepancy can be made to decrease faster the farther away one is from equilibrium, equilibrium will be achieved. This is no Liapunov function, however, because it is not continuously differentiable. It is, in fact, a simple geometric representation of the usual picture of an excess demand, demand minus supply, near equilibrium, together with an argument that if individuals are similar, and curves are linear, then demand and supply curves look "nice"; in this case the equilibrium will of course be stable.

The issue is, for assessing "priority," whether Allais's argument actually used a Liapunov function. Unambiguously the answer is no, since such a function must be continuously differentiable. ${ }^{4}$

\section{The Whig Prism through Which It Is All Seen}

I should take a brief detour here to sketch the "modern" treatment of the stability issue, for I am arguing that this present treatment has forced the past to look a certain way.

If the $i$ th market is characterized by a tâtonnement adjustment process, so that the price of the $i$ th good moves with excess demand for that good, and excess demand is a function of all prices of all $n$ goods, then we have

$$
\dot{p}_{i}=E_{i}\left(p_{1}, p_{2}, p_{3}, \ldots, p_{n}\right) \text { for } i=1,2,3, \ldots, n .
$$

The excess demand function is assumed to be continuously differentiable, homogeneous of degree zero, and to satisfy Walras's Law, so that if $p=\left(p_{1}, \ldots, p_{n}\right)$ and $E=\left(E_{1}, \ldots, E_{n}\right)$, then $\Sigma p_{i} E_{i}(p)=0$, or in vector notation, $p \cdot E(p)=0$. Assume that $p^{*}=\left(p_{1}{ }^{*}, \ldots, p_{n}{ }^{*}\right)$ is the equilibrium price vector (relative prices if there are actually $\mathbf{n}+1$ markets, or alternatively we can have $\Sigma p_{i}=1$ or $p_{n}=1$ if there are $n$ markets, etc.), and define the function $V(p)=1 / 2 \Sigma\left(p_{i}-p_{i}{ }^{*}\right)^{2}$. That is, let $V$ be a measure of the Euclidean distance of the actual price vector from the equilibrium price vector. $V$ is certainly a Liapunov function since it is a continuously differentiable function of the state variables (prices) which is everywhere non-negative and is zero if and only if the state is an equilibrium state.

Differentiating $V$ with respect to time, to see whether the system's state variables, along trajectories, approach equilibrium, we have

4. This is crucial, for the nature of a Liapunov function is that one may differentiate it with respect to time and show that its time rate of change is negative. To speak or write of a nondifferentiable Liapunov function is to commit a category mistake. 


$$
\dot{V}(p)=\Sigma \dot{p}_{i}\left(p_{i}-p_{i}^{*}\right)=\Sigma p_{i} E_{i}-\Sigma p_{i}^{*} E_{i}=-\Sigma p_{i}^{*} E_{i},
$$

where the last equality is true by reason of Walras's Law. The issue thus is one of the positivity of the equilibrium-price-weighted excess demands. Modern proofs, since Arrow, Block, and Hurwicz, depend on gross substitutability and homogeneity to infer such positivity of the last expression. Note that this expression is the negative of the sum of the values of excess demand; or, since excess demand is demand minus supply, this is the value of supply minus the value of demand. And if the value of supply exceeds the value of demand, then $V$ is decreasing. This is the connection to the interpretations of Allais's argument as being based on a Liapunov function, for Allais's work is a demonstration, based on particular assumptions, of the relationship between the value of supply and that of demand. Those values are not the values discussed here, for the values are not equilibrium-price weights.

This bit of modern analysis can be used to say that Allais "almost" used Liapunov analysis, or that his work could be presented as if he had used Liapunov analysis, or that he was doing Liapunov analysis without really knowing it, or that he "was a hair's breadth away" from Liapunov analysis, or that he had an imperfect understanding of Liapunov analysis, etc. This reconstruction of a text, this reading of Allais's 1943 work, is a reading of the past from the present in a thoroughly Whiggish manner. We see the Liapunov function because we "know" that the argument that Allais was constructing can be worked using Liapunov analysis. We know that his theorem is provable by a technique which seems to be that towards which his arguments strained. Yet though Allais seemed to use a Liapunov function, in fact he did not. His characteristic function was not necessarily continuous, let alone differentiable as a function of time. Nowhere was there an explicit dynamic system introduced, and the Liapunov function was not defined on the motions of the system. While it is possible to reconstruct Allais's argument in modern terms, as Negishi did so clearly and well in 1962, it is grossly misleading to suggest, as Belloc and Moreaux have done, that Allais either used Liapunov's second method or proved the stability of the competitive equilibrium in the sense of Arrow and Hurwicz. Allais himself has not made such a claim; his 1943 book can stand on its own considerable merits.

\section{Are Precursors Possible?}

When we speak of a precursor, we seem to suggest that at time $t-2$ an individual presented an analysis which can be reconstructed, from a "perspective" placed at time $t$, as "essentially equivalent" to an analysis "first" done at time $t-1$. What I have here problematized is the notion that the ideas of "first" and "essentially equivalent" have any meaning 
independent of the "perspective." As our perspective changes, as we know different things, what we see as similar and different changes. The well-known Gestalt femme fatale cannot be unseen as the old crone, nor can the urn be unseen as faces. My younger son, having been at age eight reminded that he at age three confused the words "pigeon" and "midget" as "pidget," can at twelve no longer see a small person without seeing a strutting bird as well.

We cannot unhear Beethoven as we hear Brahms again, and we cannot listen to Wagner's Ring in the same way after we have heard comedienne Anna Russell's Wagnerian "Guide." We think it odd to ask whether Beethoven was Brahms's "precursor." It is no different with mathematical work.

We may, of course, reconstruct the past as we wish, read the past in any one of a number of ways. Indeed we are forced to provide such readings. We are the readers, and our histories, both social and personal, are the context for our readings. We impute similar contexts to our own readers: I would construct this paragraph differently for a historian-reader.

Precursor studies seem to function then as legitimizers of a historian's interest in certain past contributors, or possibly marginalized members of a particular scientific community. Rhetorically, calling A " $B$ 's precursor," where we can assume a reading community's interest in B, legitimizes an interest in $A$, if $A$ was not hitherto well noted. In a like manner, if a hitherto unknown current B's contribution can be reconstructed as the fully articulated version of the past-famous A's almost-analysis, then A's "precursorness" may further enhance a glorious reputation. "It's all in Marshall," after all.

Or is it all in Allais?

This paper was begun while I was a fellow of the National Humanities Center, and support from the Center is gratefully acknowledged. I am grateful for comments, on an earlier draft, by Craufurd Goodwin, Jean-Michael Grandmont, Hervé Moulin, Michael Moreaux, Bernard Belloc, Randall Bausor, and Neil de Marchi, none of whom of course is responsible for the version which appears here.

\section{References}

Allais, M. 1943. A la recherche d'une discipline économique: première partie, L'économie pure. Paris: Ateliers Industria.

L 1978. Contributions à la science économique: vue d'ensemble, 19431978. Paris: Centre d'Analyse Economique.

Belloc, B., and M. Moreaux. 1987. Allais, Maurice. In The New Palgrave: A Dictionary of Economics, edited by J. Eatwell, M. Milgate, and P. Newman, 1:78-79. New York: Stockton Press.

Grandmont, J. M. 1988. Report on M. Allais' Scientific Work. CEPREMAP Discussion Paper 8819. Paris. 
Hahn, F. H. 1983. On General Equilibrium and Stability. In Paul Samuelson and Modern Economic Theory, edited by E. C. Brown and R. Solow. New York: McGraw-Hill.

Kuhn, Thomas S. [1962] 1977. The Historical Structure of Scientific Discovery. Science 136. Reprinted in The Essential Tension. Chicago: University of Chicago Press.

Merton, Robert K. 1957. Priorities in Scientific Discovery: A Chapter in the Sociology of Science. American Sociological Review 22.

Morishima, M. [1950] 1980. Dynamic Economic Theory. Author's translation of Dogakuteki Keizai Riron. London: Economics Department, London School of Economics.

Negishi, T. 1962. The Stability of a Competitive Economy: A Survey Article. Econometrica 30:635-69.

Patinkin, D. 1965. Money, Interest and Prices. 2d ed. New York: Harper \& Row. Weintraub, E. R. 1985. General Equilibrium Analysis: Studies in Appraisal. New York: Cambridge University Press.

. 1987. Stability Theory via Liapunov's Method: A Note on the Contribution of Takuma Yasui. HOPE 19.4:615-20. 